\begin{tabular}{|c|l|}
\hline Title & Growth parameters of endangered freshwater pearl mussel (Margaritifera laevis, Unionoida) \\
\hline Author(s) & A kiyama, Y oshihiro B; I Iwakuma, Toshio \\
\hline Citation & $\begin{array}{l}\text { Fundamental and A pplied Limnology /A rchiv für Hydrobiologie, 175(4), 295-305 } \\
\text { https://doi.org/10.1127/1863-9135/2009/0175-0295 }\end{array}$ \\
\hline Issue Date & 2009-12 \\
\hline Doc URL & http://hdl.handle.net/2115/43042 \\
\hline Type & article(author version) \\
\hline File Information & O-0551_A kiyama[1].pdf \\
\hline
\end{tabular}

Instructions for use 


\title{
Growth parameters of endangered freshwater pearl mussel (Margaritifera laevis, Unionoida)
}

\author{
Yoshihiro B. Akiyama* and Toshio Iwakuma ${ }^{1}$
}

With 3 figures and 3 tables

\begin{abstract}
We observed periodic increments of the annuli to verify the annual growth-age relationship in two populations of a freshwater pearl mussel, Margaritifera laevis (Bivalvia, Unionoida), in northern Japan and confirmed that one annulus is added each year. The relationship between yearly shell growth and age was regarded as a unimodal distribution. We fitted several growth models to the shell length-age relationships of these two populations, which had different densities and age distributions. The Gompertz function showed the best fit, in terms of both RSS (residual sum of squares) and the difference between the observed maximum shell length and the asymptotic shell length. The life span of M. laevis was shorter than that reported for Margaritifera margaritifera populations at higher latitudes $\left(\geq 50^{\circ} \mathrm{N}\right)$, which have been widely recognized as threatened. Margaritiferid mussels living at lower latitudes tend to have shorter life spans and smaller maximum size. These results suggest that margaritiferid mussels in southern regions such as M. laevis in Japan and M. margaritifera in Spain may be particularly vulnerable when conditions are unsuitable for juvenile mussels for prolonged periods.
\end{abstract}

Key words: growth models, Gompertz function, annuli, maximum shell length, life-span, conservation.

\section{Introduction}

Environmental characteristics greatly affect the metabolic rates of ectothermic animals such as bivalves. Many ectothermic species display metabolic acclimation to their environment; thus, even in these same species, growth rate, body size, and life span, all of which relate to metabolic rate, vary in relation to the environment. Variations in these life-history parameters influence the population dynamics of ectothermic species living in different habitats.

The freshwater pearl mussel, Margaritifera laevis (Haas) is found in Japan, the Kurile Islands and Sakhalin Island (Kohmoto 1928, Taki 1930, Kuroda 1931, Miyadi 1938, Kondo 2008). The species is declining in Japan and is therefore listed as endangered by the Ministry of the Environment of Japan (Ministry of the Environment 2007), and conservation measures for these mussels are required. Another margaritiferid species, Margaritifera margaritifera (Linnaeus) living in Europe and North America is also declining (Bespalaya et al. 2007, Frank \& Gerstmann 2007) and is also recognized as a threatened species (Young et al. 2001).

According to Comfort (1957), Awakura (1969) and Heller (1990), mussels are the longest-lived invertebrates. The life span and maximum size of M. laevis differ among populations. In five Japanese populations, the maximum age varies between 36 to 67 years, and the maximum shell length from 111 to $133 \mathrm{~mm}$ (Awakura \& Sugiwaka 1988). For both these lifehistory traits, a parameter of the exponential growth is a major determinant (Bauer 1992). This parameter determines the curvature of the growth curve, that is,

\footnotetext{
Authors' address:

${ }^{1}$ Faculty of Environmental Earth Science, Hokkaido University, N10W5, Kita-ku, Sapporo, 060-0810, Japan.

*Corresponding author; e-mail: glochi@fra.affrc.go.jp Current address: Aquaculture and Fishing Port Engineering Division, National Research Institute of Fisheries Engineering, Fisheries Research Agency, 7620-7 Hasaki, Kamisu, 314-0408, Japan.
} 
the rate at which the size approaches the maximum shell length (Bertalanffy 1938). Maximum size and life span are inversely related to the magnitude of this growth constant (Bauer 1992).

The number of eggs in marsupia of a female $M$. laevis mussel tends to increase as the mussel size increases (Awakura 1968). Margaritiferid mussels probably do not have a post-reproductive period, because it has been shown that $M$. laevis can reproduce even at 57 years of age (Awakura 1969) and M. margaritifera at over 100 years (Bauer 1987). Thus, a population of $M$. laevis with a longer life span can provide recruitment for a longer period. Since the reproductive success which depend on exogenous factors, such as the dynamics of host (larvae in Unionoida spend part of their life cycle attached to fish and/or amphibian) may vary over time, longevity decreases the vulnerability of the population. Several mathematical functions have been proposed to describe animal growth with time (Chicharo \& Chicharo 2000, Pouvreau et al. 2000, Millstein \& O'Clair 2001). Such models include a parameter for growth rate, theoretical maximum size and maximum age. These growth-model parameters have been used to assess the conservation status of $M$. margaritifera populations (Beasley \& Roberts 1999). In this species, life span and shell size are associated with productivity and various environmental factors such as water temperature and the concentration of nitrate in the water (Bauer 1992, Hastie et al. 2000a). Accurate estimation of these parameters in growth models based on age and body length helps the understanding of the life-history of M. laevis. It may be also be helpful for their conservation. However, no morphological trait indicating age has been identified in M. laevis, so an optimal growth model has not yet been developed.
The aims of the present study were (1) to confirm that growth bands are incremented annually; (2) to qualitatively verify the assumptions required for selecting the appropriate growth model from the relationship between age and the annual increment in shell length (i.e., to verify the age at which this mussel attains its annual growth peak and to determine whether the annual growth versus age curve is symmetric); and (3) to find the best descriptor of mussel growth by fitting four non linear growth models (i.e., hyperbolic saturation function, Gompertz function, logistic function, and Bertalanffy growth function), to the M. laevis length-at-age data sets and comparing their fit and performance.

\section{Methods}

\section{Sampling sites}

We obtained M. laevis specimens from one site in the Shiribetsu River in Rankoshi town and Chitose Rivers in Chitose city, Hokkaido, Japan, respectively. The Shiribetsu River is $126 \mathrm{~km}$ long and the Chitose River is $108 \mathrm{~km}$ long. Mussels, including adults and juveniles, are distributed abundantly in the lower reaches of the Shiribetsu River and in the middle reaches of the Chitose River. Such populations including abundant juvenile mussels are not common in Japan (Akiyama 2007). Thus, by using specimens from these rivers with abundant juveniles, we could ascertain the true growth model for $M$. laevis, allowing us to accurately understand the growth pattern not only during the adult stage but also during the juvenile stage. The number of mussels used for the present study was 186 individuals from the Shiribetsu River and 229 individuals from the Chistose River. In these specimens, 79 individuals in the Shiribetsu River and 229 individuals in the Chitose River were sacrificed (Table 1). License for mussel collection was obtained from the Chitose city government and Shiribetsu fisheries cooperative association in advance.

Table 1. Outline of methods for respective rivers.

\begin{tabular}{|c|c|c|c|c|}
\hline & year & Purpose & The main method & $\begin{array}{c}\text { The number of collected } \\
\text { data / samples used / } \\
\text { sacrificed per act }\end{array}$ \\
\hline \multirow[t]{3}{*}{ Shiribetsu River } & 2004 & Verification of ring increments & Observation of shell surface & $107 / 107 / 0$ \\
\hline & 2003 & Verification of growth pattern & $\begin{array}{c}\text { Boiling shell, length measurement } \\
\text { and ring count }\end{array}$ & $298 / 53 / 53 *$ \\
\hline & 2003 & Growth model fitting & $\begin{array}{l}\text { Length measurement and ring } \\
\text { count }\end{array}$ & $79 / 79 / 79$ \\
\hline \multirow[t]{2}{*}{ Chitose River } & 2003 & Verification of growth pattern & $\begin{array}{c}\text { Boiling shell, length measurement } \\
\text { and ring count }\end{array}$ & $378 / 96 / 96^{*}$ \\
\hline & 2003 & Growth model fitting & $\begin{array}{l}\text { Length measurement and ring } \\
\text { count }\end{array}$ & $229 / 229 / 229$ \\
\hline
\end{tabular}

* All of these mussels consist of a part of specimens for growth model fitting for each population. 
Fig. 1. Photographs of Margaritifera laevis shells: boiled in a $1 \mathrm{~N} \mathrm{NaOH}$ solution (top), and an untreated shell (bottom). $l i$, long axis length of the $i$ th observable annulus.
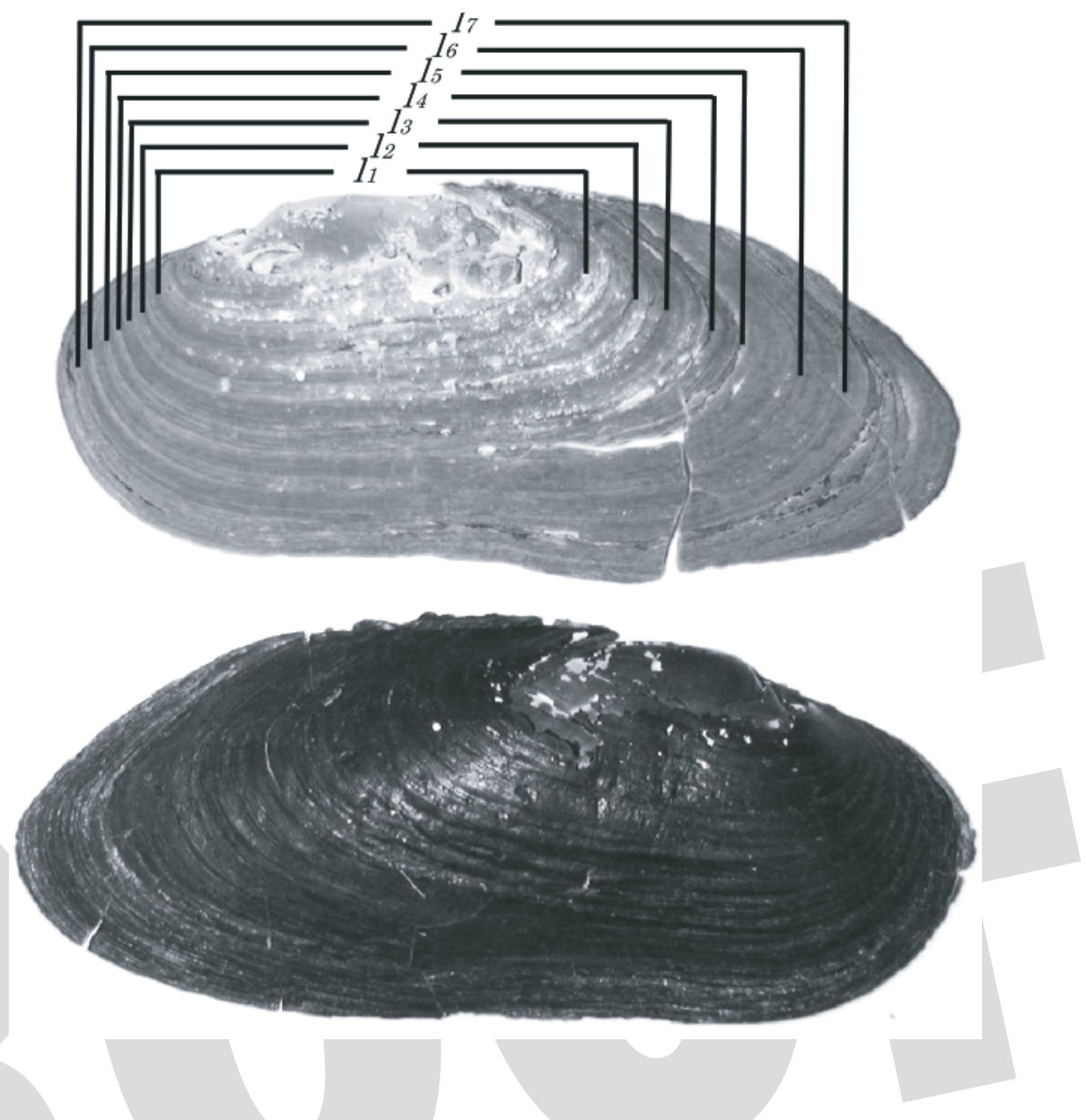

\section{Observation of annual growth ring increments on} the mussel shell surface

We hypothesized that the growth ring of M. laevis is formed in winter and yearly individual growth can be estimated from length between consecutive growth rings because the growth rings of three mussel species, Anodonta anatina, Unio tumidus and Unio pictorum belonging to the same order as M. laevis, are known to form in winter (Negus 1966). In August 2004, 107 mussels were collected randomly from the Shiribetsu River, and, after measurement of their shell lengths with a vernier caliper to within $0.01 \mathrm{~mm}$, their shell surfaces were abraded with a label by using a miniature electric drill. Immediately thereafter, the mussels were released to their original river habitats. A year later, the labeled mussels were collected again and the number of growth rings on the marginal parts of the mussel shells that had grown during the previous year was counted. The result showed that growth rings of $M$. laevis in the Chitose River increased by one each year (Akiyama 2004).

\section{Change in annual growth with age}

To verify the characteristic of the growth pattern of $M$. laevis, 53 mussels were collected from the Shiribetsu River, and 96 from the Chitose River, in 2003. The length axes of the growth rings (annuli) on the shell surface were measured with a digital caliper to within $0.01 \mathrm{~mm}$ and the differences in the long axis lengths (Fig. 1) between consecutive growth rings were ascertained. Shells with obscure growth rings were boiled in
$1 \mathrm{~N} \mathrm{NaOH}$ solution for about 10 minutes to carefully remove the periostracum and render these growth rings clearly visible. To estimate the age of the specimen, the number of growth rings was counted and recorded. We obtained these data from all specimens and combined them per river $(N=298$ for the Shiribetsu River and $N=378$ for the Chitose River) to examine the relationship between annual shell growth and age for each river. A problem arose with old specimens, because in these specimens fairly large areas around the umbo are often badly abraded, thus hampering observation of several of the earliest annuli. To avoid the problem caused by this absence of data, we corrected the ages of these specimens by using data from juvenile specimens with less erosion. A complete shell $(8.6 \mathrm{~mm}$ in shell length) without erosion from the Chitose River had growth rings that could be observed clearly. We measured the length axis of the first annulus $(0.52 \mathrm{~mm})$ of this specimen with a digital caliper to within $0.01 \mathrm{~mm}$ under a binocular microscope with $25 \times$ magnification. Kobayashi \& Kondo (2005) reported that the mean shell length of M. laevis juveniles in the Chubu-nogu River, Japan, shortly after detachment from their host fish was $470 \mu \mathrm{m}$. In addition, shell growth of juvenile M. margaritifera from different rivers is known to be rather uniform until the end of their first winter (Buddensiek 1995). These findings suggest that the first-annulus of our specimen formed in the first winter after the juvenile mussel detached from its host fish. The length-axis length of the second annulus, which formed in the next winter when the mussel was one year old was $1.33 \mathrm{~mm}$. Thus, we estimated the number of growth rings on the abraded part of the shell around the umbo on the basis of the relationship 
between shell length and the number of growth rings obtained from less eroded juvenile shells.

Fitting growth models to shell length-age relationships and comparison of growth parameters between the two populations

To investigate the growth characteristics of each population, we fitted four nonlinear growth models to the shell lengthat-age relationships. In 2003, 79 and 229 mussels, including the specimens used to verify the growth pattern, were collected from the Shiribetsu River and the Chitose River, respectively. We especially tried to catch the mussel with maximum size in each river for about an hour. The shell length of each individual was measured with a vernier caliper to within $0.01 \mathrm{~mm}$. The age of each shell was estimated according to Hendelberg's (1961) method, by which a mussel's age is determined from the number of annual layers on cut surface of its ligament. This method is suitable for the age determination of long lived mussels with thickly developed ligament and could be carried out with low cost and short labor hour, and thereby the method has often been used for Margaritiferidae (Bauer 1983, Hruska 1992, Hastie \& Toy 2008). The age estimated by the method in Hendelburg (1961) tends to be several years younger than that estimated by the method of counting annuli on the shell surface of $M$. laevis in the Chubu-Nougu River in central Japan due to obscure rings (Kobayashi \& Kondo, 2008). However, average air temperature in our sampling sites lying in northern Japan, are lower than in the study site of Kobayashi \& Kondo (2008) (Rankoshi town: $7.5^{\circ} \mathrm{C}$, Chitose city: $7.1^{\circ} \mathrm{C}$, Omachi city which is sampling site in Kobayashi \& Kondo (2008): $9.3^{\circ} \mathrm{C}$, these temperatures were calculated based on the data between 1979 to 2008 provided by Japan Meteorological Agency) with long winter (i.e., land is covered with snow for about five months in a year), and thus mussels in our sampling sites had clear and thick rings and these lines could be easily counted. Another method recommended by Neves \& Moyer (1988), which is thin-sectioning of a shell, is the most effective techniques for many mussel species, whereas, the method in Hendelberg (1961) is suitable for several species including Margaritiferidae. This is because the latter only applies to mussels with thickly developed ligament, and consequently, the method is unsuitable for genera with thin shells, e.g. Anodonta. Since the method in Hendelberg (1961) can be easily done at low cost, it is very convenient for at least some margaritiferid populations including $M$. laevis in northern Japan. After considering these facts, we eventually decided that the age estimation according to Hendelberg (1961) is a suitable method for M. laevis in our study because our specimens had distinct growth lines in well developed ligament.

In the present study, we fitted the following four growth functions to the shell length and age data. The hyperbolic saturation function, or Michaelis-Menten equation, is commonly used by ecologists (Li 1983, Kluth \& Bruelheide 2004). San Miguel et al. (2004) modified this function by adding two parameters to apply the function to a mussel population after a certain age. In the present study, we applied a three-parameter function with one additional age parameter (eq. 1). The Gompertz function (eq. 2, Gompertz 1825) is asymmetrical in relation to the inflection point, whereas the logistic function (eq. 3, Verhulst 1845 , 1847 ) is symmetrical. The Bertalanffy growth function (eq. 4, Bertalanffy 1938) does not incorporate an inflection point and is commonly used to describe growth after the initial exponential growth phase in the first year of life (Ricker 1975). Both the Gompertz function and the logistic function have been used for marine bivalves (Dean 1993, Devillers et al. 1998, Ohnishi $\&$ Akamine 2006). The Bertalanffy growth function has been widely used for freshwater mussel species, including $M$. margaritifera (Hastie et al. 2000a, King 2000). The four models are expressed by the following functions:

Hyperbolic saturation function

$$
L_{t}=\frac{L_{\infty} k\left(t-t_{0}\right)}{1+k\left(t-t_{0}\right)}
$$

Gompertz function

$$
L_{t}=L_{\infty} e^{-a e^{-k t}}
$$

Logistic function

$$
L_{t}=\frac{L_{\infty}}{1+e^{-k(t-b)}}
$$

Bertalanffy growth function

$$
L_{t}=L_{\infty}\left(1-e^{-k\left(t-t_{0}\right)}\right)
$$

where $L_{\infty}$ is the theoretical maximum length (or asymptotic length, mm), $k$ is the growth coefficient (year ${ }^{-1}$ ), $t 0$ is the theoretical age at zero length (years), and $a$ and $b$ (year) are constants. The parameter values of each function were estimated by the Gauss-Newton algorithm, which is the most common algorithm for solving nonlinear regressions (Myers 1990). The best-fitting model was selected by comparing RSS (residual sum of squares). Computer programs for all tasks were built with $\mathrm{R}$ version 2.4.1 (R Development Core Team 2006).

\section{Results}

\section{Yearly increment of growth rings on the mussel shell surface}

Forty-nine labeled mussels were collected again a year after their release. In 38 of these mussels, the shell surface had been incremented by one ring during the previous year. These 38 mussels were all less than $93.9 \mathrm{~mm}$ in shell length. In mussels larger than $98.4 \mathrm{~mm}$, and in a few mussels less than $93.9 \mathrm{~mm}$ long, the growth band increment could not be precisely confirmed because their growth rate was low and the shell surface was a dark color. Moreover, false rings had formed in 17 mussels as a result of stress caused by the mini-drill. These false rings, however, could be clearly distinguished from true growth rings because the false rings were narrow and discontinuous, especially on the anterior part of the shell.

\section{Change in annual growth with age}

Annual shell growth, as indicated by the difference in the length of the length-axis of adjacent annuli, was unimodal against age, with maximum growth reached at 5 years in the Shiribetsu River. In contrast, in the Chitose River, the relationship appeared bimodal, with 
a small peak at 3 years and a broad peak and maximum growth at 7 years. In both rivers, shell growth was gradual during the early juvenile phase, and after the mussels attained their maximum annual growth increment at the age of 5 to 7 years, it decreased gradually with age (Fig. 2).

\section{Determination of a suitable growth model}

In both populations of $M$. laevis, the growth curve was an asymmetric sigmoid curve (Fig. 3). Among the collected specimens, the maximum age and the maximum shell length were 21 years and $118.3 \mathrm{~mm}$, respectively, for the Shiribetsu River population, and 55 years and $118.4 \mathrm{~mm}$ for the Chitose River population. For both populations, the best-fitting and the second-best-fitting models were the Gompertz function and the Bertalanffy growth function (Table 2). Fitting of the Gompertz function resulted in an $L_{\infty}$ (95\% confidence intervals) value of $113.4 \mathrm{~mm}(110.0-116.7 \mathrm{~mm})$ for the Shiribetsu River population and $106.7 \mathrm{~mm}(98.1-115.3 \mathrm{~mm})$ for the Chitose River population (Table 2). These values were significantly lower than the observed maximum shell lengths. The $L_{\infty}$ values calculated for the hyperbolic function and the logistic function were significantly higher and lower than the observed values, respectively. The $L_{\infty}$ value for the population in the Shiribetsu River calculated with the Bertalanffy growth function was not significantly different from the observed value, whereas that for the population in the Chitose River was significantly higher than the observed value.

\section{Discussion}

We confirmed that the number of annuli of M. laevis increased by one each year, and that we could distinguish false rings from genuine rings. These findings indicate that the age and annual growth rate of these mussels can be estimated from the annuli on their shell surfaces. However, in the present study, we did not estimate the ages of $M$. laevis from the number of annuli but from the number of annual layers in the ligament because the former permit age estimation for mussels up to 30-40 years old, whereas the latter can be applied to mussels over 100 years (Hendelberg 1961). Even if age estimation errors (Kobayashi \& Kondo 2008) are taken into account, growth layers are incremented in the ligament roughly synchronously with the annual ring increment on the shell surface (Akiyama 2007). Accordingly, increases in annual rings and in annual layers approximately coincide, and the method of age

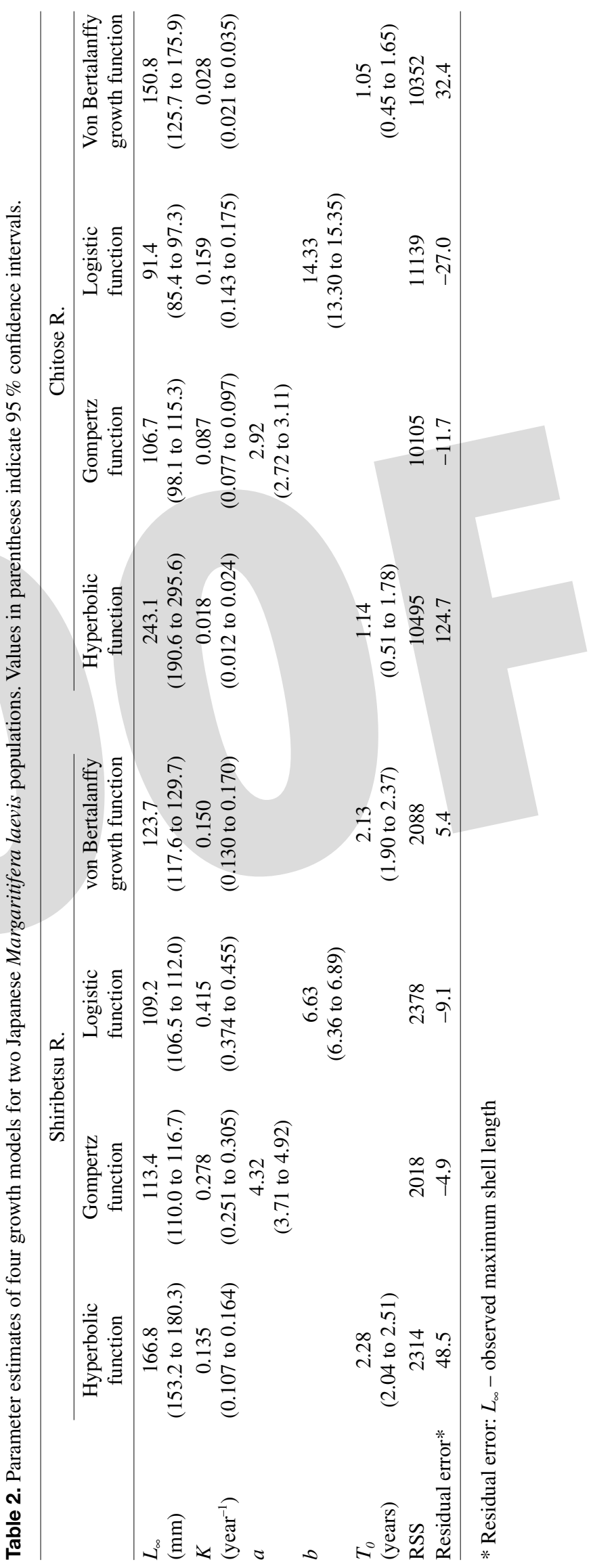




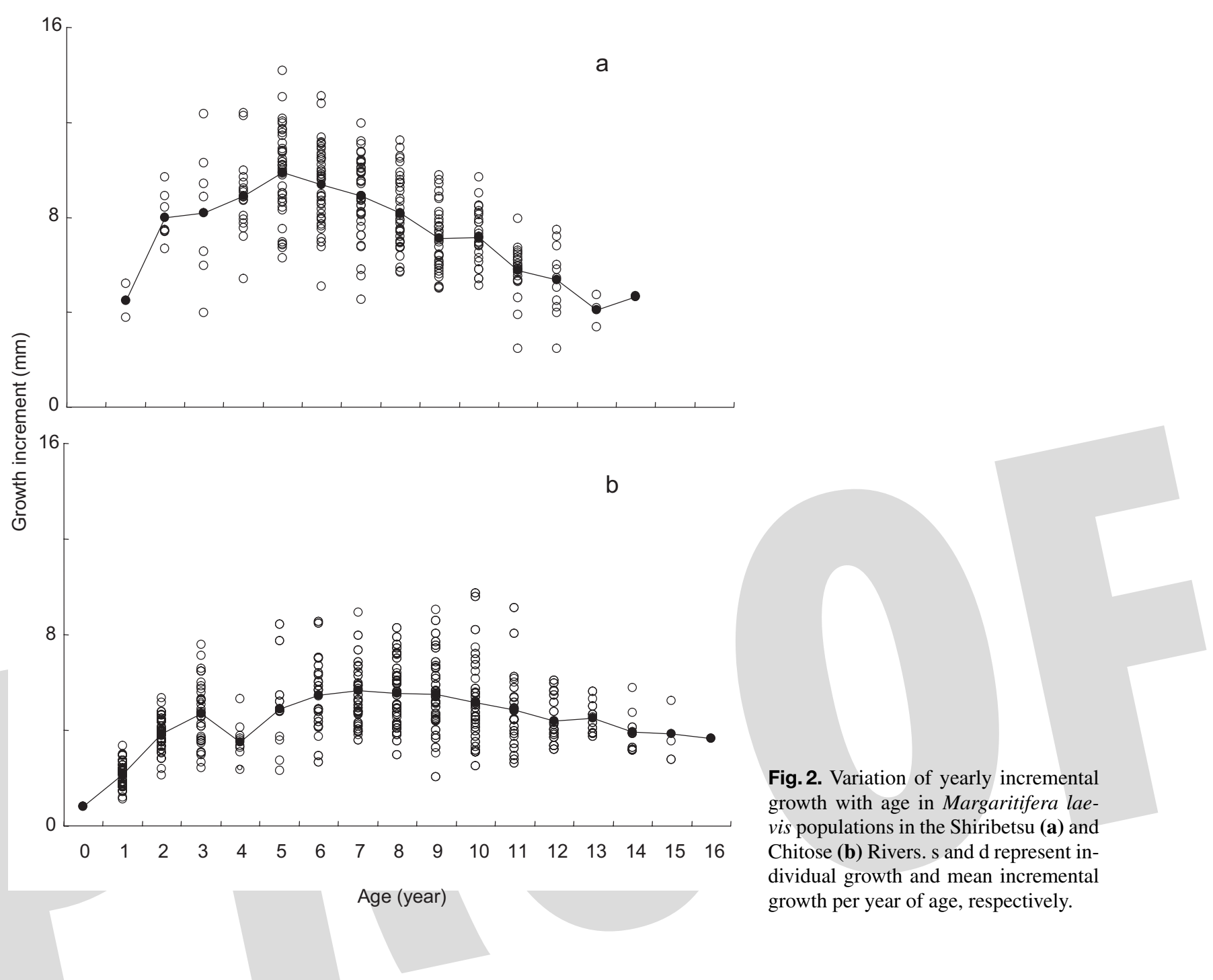

estimation from annual layers in the ligament used for M. margaritifera (Bauer 1988, Hastie et al. 2000a, 2000 b) is also applicable to M. laevis.

The annual growth increment of these mussels increased gradually with age until they reached 5 to 7 years of age, and then yearly incremental shell growth gradually decreased (Fig. 2). In the Chitose River population, the annual growth at 4 years of age was lower than that at ages 3 or 5 years. This result might reflect the small sample size of 4-year-old mussels $(n=10)$. The unimodal distribution of growth rate against age implied that the best-fitting model for the growth of M. laevis should have an inflection point. Therefore, although the Bertalanffy growth function is often used for describing margaritiferid growth (Hastie et al. 2000a, San Miguel et al. 2004, Outeiro et al. 2008), this model is unsuitable for M. laevis because it has no left-hand 'tail'. Moreover, the maximum age that mussels in the Shiribetsu and Chitose Rivers attained was 21 and 55 years, respectively. Therefore, the peak growth rate of $M$. laevis is not in the middle of its life span. These growth patterns and life spans indicate that the shape of the growth-model curve for M. laevis is asymmetrical. These facts suggest that the Gompertz function is most suitable for describing the growth of M. laevis, and, in fact, the Gompertz growth function was the best-fitting function as indicated by the lowest RSS. The Gompertz function family, which includes the Laird-Gompertz function (Laird et al. 1965), has been used as a suitable growth model for a wide range of organisms, including mammals (Bergmann et al. 2006, Mattson et al. 2006), reptiles (Hailey \& Coulson 1999), fish (Matic-Skoko et al. 2007), crustaceans (Piscart et al. 2003), echinodermata (Skold et al. 2001), and molluscs (Blanchard \& Feder 2000). However, only a few studies have used the Gompertz function for freshwater mussels (e.g., Nakagawa et al. 1998), whereas the Bertalanffy growth function is more com- 
Fig. 3. Estimated Gompertz growth curves for Margaritifera laevis populations in the Shiribetsu River (s) and the Chitose River (d).

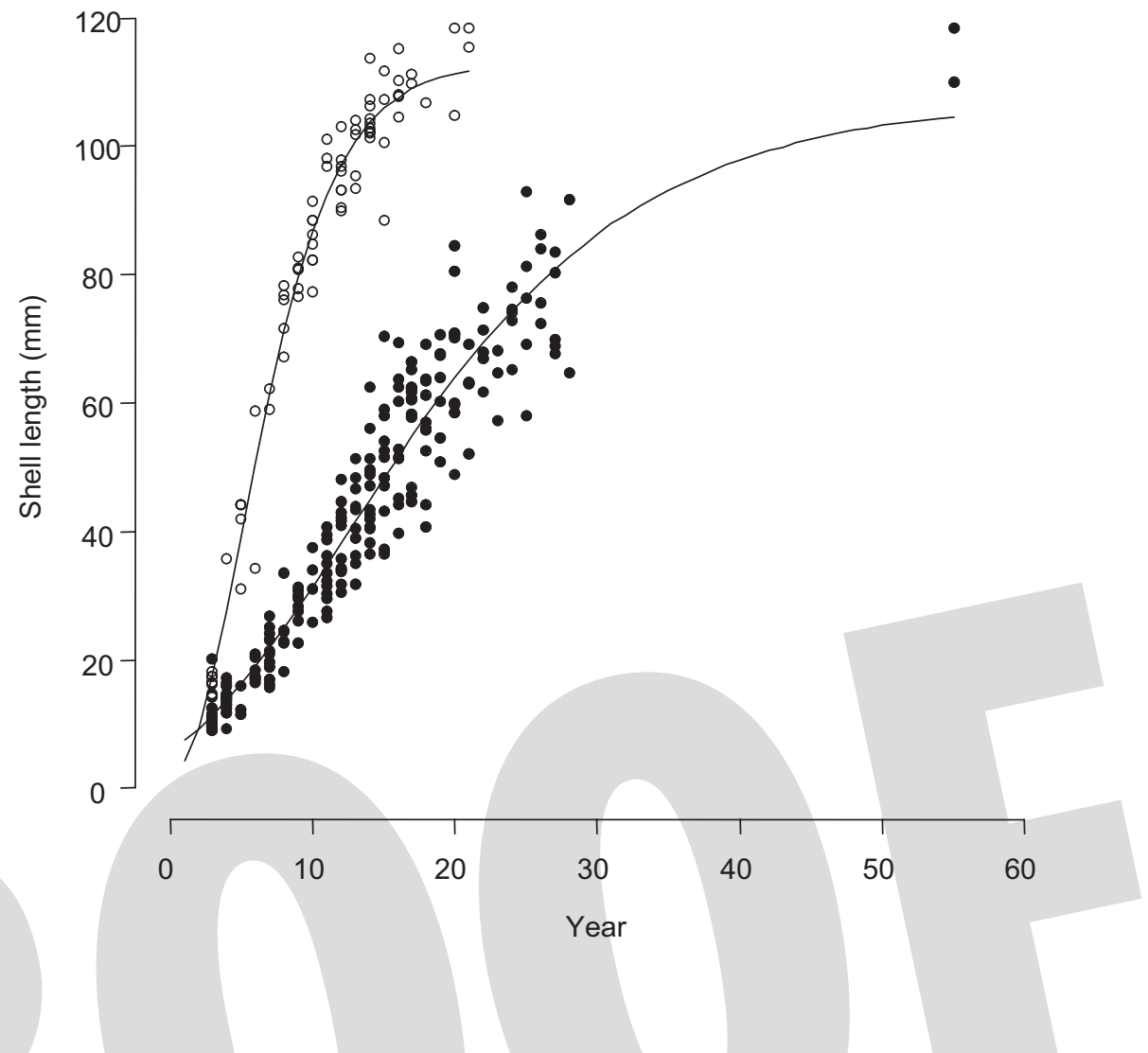

\& Sugiwaka (1988) found maximum sizes of $133 \mathrm{~mm}$ in the Shiribetsu River and $130 \mathrm{~mm}$ in the Chitose River. Thus, our findings are consistent with those of Awakura \& Sugiwaka (1988) in terms of the maximum age and maximum sizes relationships between the two rivers. The different results obtained by Bauer (1992) from our results and those of Awakura \& Sugiwaka (1988) might reflect differences in species, number of sampling sites, or spatial sampling scale. The maximum ages and maximum sizes of mussels from the Shiribetsu and Chitose Rivers were different between the present study and that by Awakura \& Sugiwaka (1988): maximum size of mussels was lower in the present study than in the study of Awakura \& Sugiwaka (1988). Maximum age of mussels was lower than the maximum age reported by Awakura \& Sugiwaka (1988) for mussels from the Chitose River, whereas the opposite was true for animals from the Shiribetsu River. It is known that M. margaritifera mussels living in the lower reaches of rivers grow faster than those living in the upper reaches and that the maximum size and maximum age differ among sampling sites along the same river (Hastie et al. 2000a). The difference in results between Awakura \& Sugiwaka (1988) and the present study even for the same rivers might thus have been caused by differences in the sampling locations or by sampling time. 
Table 3. Comparison of maximum age $\left(A_{\max }\right)$ and maximum shell length $\left(L_{\max }\right)$ among Margaritifera laevis and Margaritifera margaritifera populations. Numeric value in parenthesis is the result of the present study.

\begin{tabular}{|c|c|c|c|c|c|}
\hline Species & Country & River & $A_{\max }$ (years) & $L_{\max }(\mathrm{mm})$ & $n$ \\
\hline \multirow[t]{7}{*}{ M. laevis } & Far east Russia & Brianka & $32^{1}$ & $123^{1}$ & $23^{1}$ \\
\hline & Far east Russia & Rikardo & $28^{1}$ & $136^{1}$ & $13^{1}$ \\
\hline & Japan & Shiribetsu & $36^{2}(21)$ & $133^{2}(118.3)$ & $94^{2}$ \\
\hline & Japan & Chitose & $47^{2}(55)$ & $130^{2}(118.4)$ & $351^{2}$ \\
\hline & Japan & Shibetsu & $54^{2}$ & $121^{2}$ & $237^{2}$ \\
\hline & Japan & Masuhoro & $58^{2}$ & $113^{2}$ & $127^{2}$ \\
\hline & Japan & Shokan-betsu & $67^{2}$ & $111^{2}$ & $120^{2}$ \\
\hline \multirow[t]{25}{*}{ M. margaritifera } & Northwest Russia & Varzuga & $190^{1}$ & $120^{1}$ & $44^{1}$ \\
\hline & Northwest Russia & Thorma & $155^{1}$ & $152^{1}$ & $13^{1}$ \\
\hline & Northwest Russia & Keret & $114^{1}$ & $162^{1}$ & $16^{1}$ \\
\hline & United Kingdom & - & $95^{3}$ & $132^{3}$ & $37^{3}$ \\
\hline & United Kingdom & - & $73^{3}$ & $105^{3}$ & $52^{3}$ \\
\hline & United Kingdom & - & $69^{3}$ & $150^{3}$ & $68^{3}$ \\
\hline & United Kingdom & - & $84^{3}$ & $118^{3}$ & $87^{3}$ \\
\hline & United Kingdom & - & $110^{3}$ & $139^{3}$ & $160^{3}$ \\
\hline & United Kingdom & - & $123^{3}$ & $150^{3}$ & $82^{3}$ \\
\hline & United Kingdom & - & $102^{3}$ & $125^{3}$ & $48^{3}$ \\
\hline & United Kingdom & - & $52^{3}$ & $144^{3}$ & $65^{3}$ \\
\hline & United Kingdom & - & $48^{3}$ & $140^{3}$ & $81^{3}$ \\
\hline & United Kingdom & - & $112^{3}$ & $129^{3}$ & $31^{3}$ \\
\hline & Spain & Eo & $50^{4}$ & $111.24^{4}$ & $157^{1,4}$ \\
\hline & Spain & Landro & $44^{4}$ & $117.32^{4}$ & $53^{1,4}$ \\
\hline & Spain & Masma & $45^{4}$ & $98.37^{4}$ & $90^{1,4}$ \\
\hline & Spain & Mera & $49^{4}$ & $96.77^{4}$ & $69^{1,4}$ \\
\hline & Spain & Ouro & $64^{4}$ & $103.13^{4}$ & $84^{1,4}$ \\
\hline & Spain & Ulla & $45^{4}$ & $99.9^{1}$ & $52^{1,4}$ \\
\hline & Spain & Arnego & $48^{4}$ & $90.5^{4}$ & $22^{4}$ \\
\hline & Spain & Mandeo & $38^{4}$ & $111.24^{4}$ & $38^{4}$ \\
\hline & Spain & Narcea & $35^{4}$ & $99.76^{4}$ & $12^{4}$ \\
\hline & Spain & Narla & $53^{4}$ & $101.65^{4}$ & $30^{4}$ \\
\hline & Spain & Tambre & $65^{4}$ & $106.67^{4}$ & $27^{4}$ \\
\hline & Spain & Trimaz & $52^{4}$ & $90.56^{4}$ & $22^{4}$ \\
\hline
\end{tabular}

Sources: ${ }^{1}$ Ziuganov et al. (2000); ${ }^{2}$ Awakura \& Sugiwaka (1988); ${ }^{3}$ Hastie et al. (2000a); ${ }^{4}$ San Miguel et al. (2004)

Although the growth coefficients $(k)$ calculated for the four growth functions were all higher in the Shiribetsu River population, the theoretical maximum size $\left(L_{\infty}\right)$ associated with fecundity was larger in the Shiribetsu River when the Gompertz and logistic functions were fitted. However, $L_{\infty}$ was larger in the Chitose River population when the hyperbolic saturation and Bertalanffy growth functions were fitted (Table 2). Thus, the comparative assessment of the two populations based on the growth-model parameters depended on the specific growth model used. Differences between the observed maximum shell length and $L_{\infty}$ were smallest when $L_{\infty}$ was estimated with the Gompertz function (Table 2). Therefore, we considered $L_{\infty}$ estimated with the Gompertz function to be optimal, even though this function underestimated $L_{\infty}$ somewhat (Table 2). In $M$. margaritifera, the $L_{\infty}$ value calculated with the Bertalanffy growth function was also underestimated except in a population with a short life span (i.e., maximum age of 35 years; San Miguel et al. 2004). In contrast, the $L_{\infty}$ value for the same population calculated with the hyperbolic growth function was overestimated (San Miguel et al. 2004). Therefore, these errors should be taken into account when using $L_{\infty}$ to assess fecundity in Margaritiferidae.

$A_{\max }$ and $L_{\max }$ in margaritiferid mussels differ among species, and variation within species across countries and populations can also be observed (Table 3). In terms of $A m_{a x}$, no old mussel with the age over one hundred year has been reported in M. laevis. However, such old mussels have often been found in populations of M. margaritifera, especially in high latitude areas, 
i.e. northwest Russia and UK, consistent with the fact that lifespan of $M$. margaritifera tend to be longer at higher latitude (Bauer 1992). Mussels in populations of M. margaritifera in Spain, the southernmost distribution area for the species in Europe (Young et al. 2001), have a lifespan similar to that of M. laevis (Table 3). Margaritiferid mussels probably do not have a postreproductive period (Awakura 1969, Bauer 1987), and M. laevis and M. margaritifera reach sexual maturity when they are about 13 (Akiyama 2007) and 12-13 years old in Scotland (Young \& Williams 1984), respectively. These results suggest that the reproductive period in M. laevis is shorter than that of M. margaritifera in higher latitudinal areas. Populations without juveniles are often observed in both margaritiferid species (Lucey 1993, Beasley et al. 1998, Alvarez et al. 2000, Cosgrove et al, 2000, Akiyama 2007) due to higher survival rate in adult mussels (Bauer 2001). These facts indicate that long-lived adults contribute to persistence of a population even when recruitment fails continually for several decades. If unsuitable environment prevents juvenile recruitment for a long period, population persistence will be dependent upon survival of adult mussels. Accordingly, under unsuitable habitat for juveniles, a M. laevis population is more vulnerable than a $M$. margaritifera population at high latitude because of its shorter lifespan.

$L_{\max }$ in $M$. laevis was generally larger than that in M. margaritifera in Spain, but not larger than that in other countries. Although the fecundity of $M$. laevis may be correlated with shell length (Awakura 1968), the relationship is not common in $M$. margaritifera (Bauer 1998). Several causes should be considered to explain the result. If a mature mussel spends much energy for reproduction, growth rate may be reduced due to energy trade-off between reproduction and growth. Moreover, in this species, the value of immediate selfpreservation of energy is high in relation to immediate reproduction (Sibly \& Calow 1986). Thus, if environment factors that affect growth rate of mussels change rapidly on a very small spatial scales during several years, fecundities of individual mussels will not be correlated with their shell lengths. In the present study, mussel fecundity showed a clear correlation with shell length; however shell length might reflect effects of some endogenous factors such as variation in metabolism and reproductive effort depending on environmental changes.

At lower latitudes such as in Japan and Spain, extinction of populations in M. laevis and M. margaritifera may occur more rapidly under unfavorable environmental conditions due to the shorter lifespan of the organisms after detachment from the host and free-living phase of larvae in high water temperature (Bauer 1992, Buddensiek 1995, Zimmerman \& Neves 2002, Akiyama \& Iwakuma 2007). Monitoring of margaritiferid populations is necessary to detect changes in vulnerable populations earlier and to take prompt action for conservation, especially for low-latitude populations.

\section{Acknowledgements}

We wish to thank two anonymous reviewers for their valuable comments on the manuscript. This study was supported by Grant-in-Aid for the 21st Century COE Program and a Grantin-Aid for Scientific Research, both from the Ministry of Education, Culture, Sports, Science and Technology through the Japan Society for the Promotion of Science.

\section{References}

Akiyama, Y., 2004: Examination of methods for age and growth determination of a long-lived freshwater bivalve, Margaritifera laevis. - Ms. Thesis. Hokkaido Univ.

Akiyama, Y., 2007: Factors causing extinction of a freshwater pearl mussel, Margaritifera laevis in Japan (Bivalvia: Unionoida). - Ph. D. Thesis. Hokkaido Univ.

Akiyama, Y. \& Iwakuma, T., 2007: Survival of glochidial larvae of the freshwater pearl mussel, Margaritifera laevis $(\mathrm{Bi}-$ valvia: Unionoida), at different temperatures: A comparison between two populations with and without recruitment. Zool. Sci. 24: 890-893.

Alvarez, C. C., Garcia-Roves, P., Ocharan, R., Cabal, J. A., Ocharan, F. J. \& Alvarez, M. A., 2000: A new record of the freshwater pearl mussel Margaritifera margaritifera L. (Bivalvia, Unionoida) from the River Narcea (Asturias, northwestern Spain). - Aquat. Conserv.: Mar. Freshwat. Ecosyst. 10: $93-102$.

Awakura, T., 1968: The ecology of parasitic glochidia of the fresh-water pearl mussel, Margaritifera laevis (Haas). - Sci. Rep. Hokkaido Fish Hatchery 23: 1-21.

Awakura, T., 1969: On the correlation between the age composition of the freshwater pearl mussel, Margaritifera laevis (Haas) and the population size of salmonid fishes. - Sci. Rep. Hokkaido Fish Hatchery 24: 55-88.

Awakura, T. \& Sugiwaka, K., 1988: Age and growth of freshwater pearl mussel, Margaritifera laevis. - Fish and Water 25: 41-44.

Bauer, G., 1983: Age structure, age specific mortality rates and population trend of the freshwater pearl mussel (Margaritifera margaritifera) in North Bavaria. - Arch. Hydrobiol. 98: 523-532.

Bauer, G., 1987: Reproductive strategy of the freshwater pearl mussel Margaritifera margaritifera. - J. Anim. Ecol. 56: 691-704.

Bauer, G., 1988: Threats to the freshwater pearl mussel Margaritifera margaritifera L. in central Europe. - Biol. Conserv. 45: 239-253.

Bauer, G., 1992: Variation in the life span and size of the freshwater pearl mussel. - J. Anim. Ecol. 61: 425-436.

Bauer, G., 1998: Allocation policy of female freshwater pearl mussels. - Oecologia 117: 90-94. 
Bauer, G., 2001: Factors affecting naiad occurrence and abundance. - In: Bauer, G. \& Wachtler, K. (eds): Ecology and evolution of the freshwater mussels Unionoida, Ecological Studies 145. - Springer-Verlag, Berlin, Heidelberg, pp. 155357.

Beasley, C. R. \& Roberts, D. 1999: Assessing the conservation status of the freshwater pearl mussel in the North of Ireland relevance of growth and age characteristics. - J. Conchol. 36: 53-61.

Beasley, C. R., Roberts, D. \& Mackie, T. G., 1998: Does the freshwater pearl mussel, Margaritifera margaritifera L., face extinction in Northern Ireland ? - Aquat. Conserv.: Mar. Freshw. Ecosyst. 8: 265-272.

Bergmann, P. J., Melin, A. D. \& Russell, A. P., 2006: Differential segmental growth of the vertebral column of the rat (Rattus norvegicus). - Zool. 109: 54-65.

Bertalanffy, L. von, 1938: A quantitative theory of organic growth (inquiries on growth laws. II). - Hum. Biol. 10: 181213.

Bespalaya, Y. V., Bolotov, I. N. \& Makhrov A. A., 2007: State of the population of the European pearl mussel Margaritifera margaritifera (L.) (Mollusca, Margaritiferidae) at the northeastern boundary of its range (Solza River, White Sea Basin). - Russ. J. Ecol. 38: 204-211.

Blanchard, A. \& Feder, H. M., 2000: Shell growth of Mytilus trossulus Gould, 1850, in Port Valdez, Alaska. - Veliger 43: 34-42.

Buddensiek, V., 1995: The culture of juvenile freshwater pearl mussels Margaritifera margaritifera L. in cages: a contribution to conservation programmes and the knowledge of habitat requirements. - Biol. Conserv. 74: 33-40.

Chicharo, L. M. Z. \& Chicharo, M. A., 2000: Estimation of the life history parameters of Mytilus galloprovincialis (Lamarck) larvae in a coastal lagoon (Ria Formosa - south Portugal). - J. Exp. Mar. Biol. Ecol. 243: 81-94.

Comfort, A., 1957: The duration of life in Mollusks. - Proc. Malacol. Soc. Lond. 32: 219-241.

Cosgrove, P. J., Young, M. R., Hastie, L. C., Gaywood, M. \& Boon, P. J., 2000: The status of the freshwater pearl mussel Margaritifera margaritifera Linn. In Scotland. - Aquat. Conserv.: Mar. Freshwat. Ecosyst. 10: 197-208.

Czarnoleski, M., Kozlowski, J., Stanczykowska, A. \& Lewandowski, K., 2003: Optimal resource allocation explains growth curve diversity in zebra mussels. - Evol. Ecol. Res. 5: 571-587.

Dean, H. K., 1993: A population study of the bivalve Idas argenteus Jeffreys, 1876, (Bivalvia: Mytilidae) recovered from a submerged wood block in the deep North Atlantic Ocean. - Malacologia 35: 21-41.

Devillers, N., Eversole, A. G. \& Isely, J. J., 1998: A comparison of four growth models for evaluating growth of the northern quahog Mercenaria mercenaria (L.). - J. Shellfish. Res. 17: 191-194.

Frank, H. \& Gerstmann, S., 2007: Declining populations of freshwater pearl mussels (Margaritifera margaritifera) are burdened with heavy metals and DDT/DDE. - Ambio 36: 571-574.

Gompertz, B., 1825: On the nature of the function expressive of the law of human mortality, and on a new mode of determining the value of life contingencies. - Philos. Transact. R. Soc. London 115: 513-583.Hailey, A. \& Coulson, I. M. 1999: The growth pattern of the African tortoise Geochelone pardalis and other chelonians. - Can. J. Zool. 77: 181-193.
Hastie, L. C. \& Toy K. A., 2008: Changes in density, age structure and age-specific mortality in two western pearlshell (Margaritifera falcata) populations in Washington (19952006). - Aquat. Conserv. Mar. Freshwat. Ecosyst. 18: 671678.

Hastie, L. C., Young, M. R. \& Boon, P. J., 2000a: Growth characteristics of freshwater pearl mussels, Margaritifera margaritifera (L.). - Freshwat. Biol. 43: 243-256.

Hastie, L. C., Young, M. R., Boon, P. J., Cosgrove, P. J. \& Henninger, B., 2000b: Sizes, densities and age structures of Scottish Margaritifera margaritifera (L.) populations. - Aquat. Conserv. Mar. Freshwat. Ecosyst., 10: 229-247.

Helama, S. \& Valovirta, L., 2007: Shell morphometry, pre-mortal taphonomy and ontogeny-related growth characteristics of freshwater pearl mussel in northern Finland. - Ann. Zool. Fennici 44: 285-302.

Heller, J., 1990: Longevity in Molluscs. - Malacologia 31: 259-295.

Hendelberg. J., 1961: The fresh-water pearl mussel, Margaritifera margaritifera (L.). - Rep. Inst. Freshwat. Res. Drottningholm 41: 149-171.

Hruska, J., 1992: The freshwater pearl mussel in South Bohemia: Evaluation of the effect of temperature on reproduction, growth and age structure of the population. - Arch. Hydrobiol. 126: 181-191.

King, R. P., 2000: Population structure, growth performance and mortality rates of the freshwater clam Galatea paradoxa (Born, 1778) in Nun River, Nigeria. - Arch. Fish. Mar. Res. 48: $21-30$.

Kluth, C. \& Bruelheide, H., 2004: Using standardized sampling designs from population ecology to assess biodiversity patterns of therophyte vegetation across scales. - J. Biogeogr. 31: 363-377.

Kobayashi, O. \& Kondo, T., 2005: Difference in host preference between two populations of the freshwater pearl mussel Margaritifera laevis (Bivalvia: Margaritiferidae) in the Shinano River system, Japan. - Venus 64: 63-70.

Kobayashi, O. \& Kondo, T., 2008: Age determination of the freshwater pearl mussel Margaritifera laevis (Bivalvia: Margaritiferidae) in the Chubu-Nougu River, Nagano Prefecture. - Venus 67: 61-71.

Kohmoto, T., 1928: Freshwater pearl mussel in the Yamaguchi prefecture. - Venus 1: 15-18.

Kondo, T., 2008: Monograph of Unionoida in Japan (Mollusca: Bivalvia). - Special Publication of the Malacological Society of Japan 3. - The Malacological Society of Japan. 69 pp.

Kuroda, T., 1931: Superfamily Naiadacea. - Venus 2: 57-74.

Laird, A. K., Tyler, S. A. \& Barton, A. D., 1965: Dynamics of normal growth. - Growth 29: 233-248.

Li, W. K. W., 1983: Consideration of errors in estimating kinetic-parameters based on Michaelis-Menten formalism in microbial ecology. - Limnol. Oceanogr. 28: 185-190.

Lucey, J., 1993: The distribution of Margaritifera margaritifera (L.) in southern Irish rivers and streams. - J. Conchol. 34: 301-310.

Matic-Skoko, S., Kraljevic, M., Dulcic, J., Pallaoro, A., Lucic, D. \& Glamuzina, B., 2007: Growth of juveniles sharpsnout seabream, Diplodus puntazzo (Teleostei: Sparidae) in the Kornati Archipelago, eastern Adriatic sea. - Vie Milieu 57: 13-19. 
Mattson, M. C., Ingram, G. W. Jr. \& Hoggard, W., 2006: Age structure and growth of the bottlenose dolphin (Tursiops truncatus) from strandings in the Mississippi sound region of the North-central Gulf of Mexico from 1986 to 2003. - Mar. Mamm Sci. 22: 654-666.

Millstein, J. \& O'Clair, C. E., 2001: Comparison of age-length and growth-increment general growth models of the Schnute type in the Pacific Blue Mussel, Mytilus trossulus Gould. - J. Exp. Mar. Biol. Ecol. 262: 155-176.

Ministry of the Environment, 2007: Red list of Japanese Endangered Wildlife, Mollusca. - Biodiversity Center of Japan - http://www.biodic.go.jp/rdb/rdb_f.html

Miyadi, D., 1938: Terrestrial water animals in the Kunashiri Island. - Jap. J. Limnol. 8: 330-339.

Myers, R. H., 1990: Classical and Modern Regression Analysis with Applications. 2nd ed. - Duxbury, Belmont.

Nakagawa, S., Deno, T. \& Kondo T 1998: Growth and development of larvae of Pseudodon omiensis. - Mem. Osaka kyoiku. Univ. III, Nat. Sci. Appl. Sci. 46: 181-186.

Negus, C. L., 1996: A quantitative study of growth and production of Unionid mussels in the River Thames at reading. - J. Anim. Ecol. 35: 513-532.

Neves, R. J. \& Moyer, S. N., 1988: Evaluation of techniques for age determination of freshwater mussels (Unionidae). Amer. Malacol. Bull. 6: 179-188.

Ohnishi, S. \& Akamine, T., 2006: Extension of von Bertalanffy growth model incorporating growth patterns of soft and hard tissues in bivalve molluscs. - Fish. Sci. 72: 787-795.

Outeiro, A., Ondina, P., Fernandez, C., Amaro, R. \& San Miguel, E., 2008: Population density and age structure of the freshwater pearl mussel, Margaritifera margaritifera, in two Iberian rivers. - Freshwat. Biol. 53: 485-496.

Piscart, C., Devin, S., Beisei, J. N. \& Moreteau, J. C., 2003: Growth-related life-history traits of an invasive gammarid species: evaluation with a Laird-Gompertz model. - Can. J. Zool. 81: 2006-2014.

Pouvreau, S., Tiapari, J., Gangnery, A., Lagarde, F., Garnier, M., Teissier, H., Haumani, G., Buestel, D. \& Bodoy, A., 2000: Growth of the black-lip pearl oyster, Pinctada margaritifera, in suspended culture under hydrobiological conditions of Takapoto lagoon (French Polynesia). - Aquacult. 184: $133-154$.

Submitted: 3 February 2009; accepted: 9 October 2009.
R Development Core Team, 2006: R : A language and environment for statistical computing. - R Foundation for Statistical Computing, Vienna.

Ricker, W. E., 1975: Computation and interpretation of biological statistics of fish populations. - Bull. Fish. Res. Board Can. 191: pp. 1-382.

San Miguel, E., Monserrat, S., Fernandez, C., Amaro, R., Hermida, M., Ondina, P. \& Altaba, C. R., 2004: Growth models and longevity of freshwater pearl mussels (Margaritifera margaritifera) in Spain. - Can. J. Zool. 82: 1370-1379.

Sibly, R. M. \& Calow, P, 1986: Physiological ecology of animals. Blackwell scientific - Oxford.

Skold, M., Josefson, A. B. \& Loo, L. O., 2001: Sigmoidal growth in the brittle star Amphiura filiformis (Echinodermata: Ophiuroidea). - Mar. Biol. 139: 519-526.

Taki, I., 1930: Margaritiferidae in Japan. - Venus 11: 98.

Verhulst, P. F., 1845: Recherches mathématiques sur la loi d'accroissement de la population. - Nouv. Mem. Acad. Roy. Sci. Lett. Belg. 18: 1-41.

Verhulst, P. F., 1847: Deuxieme memoire sur la loi d'accroissement de la population. - Mem. Acad. Roy. Sci. Belleslett. Bruxelles. 20: 1-32.

Young, M. \& Williams, J., 1984: The reproductive biology of the freshwater pearl mussel Margaritifera margaritifera (Linn.) in Scotland 1. Field studies. - Arch Hydrobiol. 99: 405-422.

Young, M. R., Cosgrove, P. J. \& Hastie, L. C., 2001: The extent of, and causes for, the decline of a highly threatened naiad: Margaritifera margaritifera. - In: Bauer, G. \& Wachtler, K. (eds): Ecology and evolution of the freshwater mussels Unionoida, Ecological Studies 145. - Springer-Verlag, Berlin, Heidelberg, pp. 337-357.

Zimmerman, L. L. \& Neves, R. J., 2002: Effects of temperature on duration of viability for glochidia of freshwater mussels (Bivalvia: Unionidae). - Amer. Malacol. Bull. 17: 31-35.

Ziuganov, V., Miguel, E. S., Neves, R. J., Longa, A., Fernandez, C., Amaro, R., Beletsky, V., Popkovitch, E., Kaliuzhin, S. \& Jonson, T., 2000: Life span variation of the freshwater pearl shell: a model species for testing longevity mechanisms in animals. - Ambio 29: 102-105. 